\title{
LIDERAZGOS INDÍGENAS EN LAS MISIONES JESUÍTICAS. TÍTULOS DE CAPITANES CONCEDIDOS A LOS CACIQUES GUARANÍES EN EL SIGLO XVII
}

\section{María Laura Salinas}

Existe una valiosa documentación que nos aproxima a través de interesantes descripciones a conocer desde la óptica jesuítica algunas características de los caciques guaraníes, sus acciones y su importancia en la consolidación de las reducciones a mediados del siglo XVII.

Al igual que en las reducciones administradas por otras órdenes religiosas, los caciques cumplieron una importante labor en la conformación de los pueblos y en los primeros tiempos de organización de cada uno de ellos. Las estrategias de aproximación de los padres de la Compañía a un determinado grupo indígena incluían en principio la relación con sus caciques y eran éstos quienes lograban que los otros líderes con sus parcialidades se acercaran. El P. Lorenzana escribía en los tiempos de la organización de San Ignacio Guazú:

“...nueve caciques, todos ellos muy cuerdos, se han ofrecido a venirse con su gente desde luego, y han comenzado algunos de ellos a hacer sus rozas, que es la mejor señal que podíamos tener"1

Los guaraníes, en este período, dado el contexto en el que se encontraban, sufrían una especie de encierro: por un lado los españoles, por otro la invasión lusitana. De ahí que la llegada de los jesuitas pudo constituir una suerte de solución para ellos ya que les prometían la roza nueva y una serie de herramientas de metal. Los mismos jesuitas decían que prometer un roza o campo de labranza nueva constituía un triunfo de dos o tres cacicazgos "que vienen junto a nosotros y se nos entregan y vienen en nuestras reducciones"2. Los conflictos permanentes probablemente desequilibraron las jefaturas guaraníes y la alianza de los caciques con los religiosos contribuyó a consolidar viejas estructuras de poder local para enfrentarse a enemigos más fuertes y poderosos.

Los liderazgos en las reducciones jesuíticas en esta primera etapa de organización de las misiones están relacionados entre otros aspectos, con las milicias, que como sistema defensivo también se encontraba en su fase organizativa y de primeras participaciones de los guaraníes hacia dos frentes: por un lado los enfrentamientos con sus tradicionales enemigos y por otro lado ante los eventuales ataques de los portugueses.

\footnotetext{
${ }^{1}$ Antonio Astrain. Jesuitas, guaraníes y encomenderos. Historia de la Compañía de Jesús en el Paraguay. Asunción, Centro de Estudios paraguayos- Fundación Paracuaria. 1996. Pág. 75.

${ }^{2}$ Branislava Susnik. El rol de los indígenas en la formación y vivencia del Paraguay. Asunción, Instituto paraguayo de Estudios Nacionales. Tomo I, 1982. Pág 162.
} 
El P. Montoya había conseguido licencia para que los indios utilicen las armas de fuego y se procuró desde 1640 aproximadamente enseñarles el arte militar. Por medio de los hermanos coadjutores que habían sido soldados y de algunos españoles diestros en las armas se fueron habituando los indios al movimiento y manejo como los ejércitos europeos.

Una de las descripciones más antiguas que nos transmiten en forma bastante detallada las características del funcionamiento de estas milicias en estos territorios es el libro III del jesuita Francisco Xarque.

"En cada pueblo ay compañías de soldados de a pie, y de a
caballo, que se componen de todos los hombres capaces de
tomar armas, cada una con su capitán, alférez, sargento, cabos de
escuadra y los demás oficiales que se acostumbran en la milicia,
con sus insignias, cajas, clarines y vanderas...en la forma que usa
nuestra España en las campañas y fronteras mejor asistidas"3

La defensa con armas, en esta primera etapa, estaba dirigida específicamente hacia los ataques portugueses, ya que otro tipo de amenazas, como las de las etnias no reducidas, no requerían el uso de dichos armamentos, según el testimonio de los propios jesuitas.

"a los infieles aunque muy vecinos poco le temen ya en las reducciones, porque siendo más numerosas éstas y pudiendo convocar a otras cercanas, con armas de fuego, caballos y lanzas, no hay fuerza en los gentiles para que presuman vencerlos. Por ello los más solicitan amistad con las reducciones y los que no la quieren se retiran cuanto más lejos pueden"... ${ }^{4}$

En la estructura de estas milicias, uno de los aspectos más significativos fueron los títulos recibidos en mayor medida por los caciques para ejercer funciones militares. En los primeros tiempos la designación de los capitanes se hacía en los mismos pueblos, el Padre Lorenzana realizó las indicaciones pertinentes en San Ignacio Guazú:

“..logró que escogieran un capitán, cosa difícil pues no estaban acostumbrados a reconocer jamás otro superior que a su propio cacique" ${ }^{5}$

Luego las designaciones se hicieron desde la gobernación o de funcionarios de alto rango. Concretamente se concedieron títulos de capitanes, frente al avance portugués y por la necesidad de defensa de las provincias del Uruguay. También se concedieron cargos destacados en las reducciones: ministros de justicia y guerra, maese de campo, por ejemplo.

\footnotetext{
${ }^{3}$ Francisco Xarque,. Libro III titulado: Estado que al presente gozan las Misiones de la Compañía de Jesús en las provincias del Tucumán, Paraguay y Río de la Plata. En: Insignes misioneros de la Compañía de Jesús, etc. Pamplona, 1687. pp. 312-313.

${ }^{4}$ Ibídem

${ }^{5}$ Antonio Astrain. Ob.Cit, pp. 77
} 
Sobre todo del siglo XVII nos han quedado datos importantes en la documentación sobre la concesión de estos títulos.

En 1640 el gobernador del Río de la Plata Don Ventura Múxica nombró a don Nicolás Nenguirú ${ }^{6}$, capitán de la reducción de Concepción, a don Francisco Bairoba, capitán de la reducción de San Nicolás, don Teodoro Iambatay de la reducción de San Carlos, don Francisco Abié de la reducción de San Miguel, don Roque Guiracazú de la reducción de San Cosme ${ }^{7}$

También se guardan referencias respecto del nombramiento de los caciques en otros cargos como maese de campo, por ejemplo, en 1639 el gobernador Pedro de Lugo y Navarro nombró a don Antón Arambaré con este oficio en la reducción de Itapúa. ${ }^{8}$

Se describen algunas dotes específicas que deben tener dichos indios para ser beneficiados con estos títulos, por ejemplo cuando se realiza el nombramiento de Superior Capitán general y justicia mayor de las reducciones del Uruguay a don Ignacio Abierú de la reducción de la Asunción de Bororé.

“ indio de valor que se había señalado en las ocasiones contra los portugueses de San Pablo que han venido a infestar las dichas reducciones entre los demás indios en servicio de las dos majestades y de su patria y que era amado y temido y respetado entre todos los indios". ${ }^{9}$

Y por otra parte en el mismo documento se menciona con respecto al nombramiento “...en todo acudiréis con mucho cuidado y puntualidad y mando a todos los caciques, curacas y demás indios os tengan y respeten por tal capitán general a guerra....cumplan y haga lo que les mandara sin excusa alguna..."

En este aspecto las fuentes jesuíticas concuerdan en que "los indios no poseían el valor audaz y acometedor, tan propio de los antiguos aventureros españoles.

\footnotetext{
${ }^{6}$ Nicolás Nenguirú, fue cabeza de una dinastía de caciques en Concepción. Fue quien pidió reducción para los suyos al padre Boroa, por el cual el P. Roque González de Santa Cruz fundó el 8/XII/ 1619 el pueblo de Concepción para su parcialidad. Fue fiel a su palabra, y entre 1637 y 1639 capitaneó las milicias guaraníes en Caazapá Miní y en Caazapá Guazú contra los portugueses. Si bien no fue mencionado en las Anuas de esos años, estos anales reivindican su figura. En una carta del Padre Boroa al rey fechada en Córdoba, 11/ IX/ 1639, se menciona a "Nicolás Nenguirú, capitán a guerra, por vuestro gobernador del Río de la Plata... que con los indios sus soldados había alcanzado la victoria". Cartas Anuas de la Provincia Jesuítica del Paraguay 1641 a 1643. Documentos de Geohistoria Regional №11. Instituto de Investigaciones Geohistóricas. Resistencia, Chaco 1996.Pág. 9.

${ }^{7}$ Títulos de capitanes y otros ministros de justicia y guerra que los gobernadores han dado a los indios del Paraná y Uruguay. Archivo Nacional de Chile. Vol. 203. ( 1625-1766) ํำ 2.

${ }^{8}$ Ibídem.

${ }^{9}$ Ibídem.

${ }^{10}$ Ibídem.
} 
Mucho menos aparecieron entre los indios las cualidades de previsión, buen orden y acertada dirección que deben distinguir a todo buen capitán"....”en cambio se distinguían por el valor de resistencia, por la tenacidad en mantener las posiciones que se les encargaban y la obediencia a sus cabos". ${ }^{11} \mathrm{Al}$ respecto el P. Xarque tiene conceptos similares: ..." aquellos indios necesitan siempre que los gobiernen cabos españoles...porque de su cosecha los indios no saben delinear un ejército, ordenar los escuadrones, dividir las compañías, acomodar los soldados....sólo a montón pelean cargando con suma gritería sobre el enemigo...pelean como leones, sin temor alguno..."12

El rol de los caciques fue fundamental en la construcción permanente de la alianza jesuítico-guaraní. Mientras los padres de la compañía mantenían el poder y las definiciones en el orden externo, hacia el interior de las reducciones el cacicazgo detentaba amplias potestades en la dirección política y militar de los pueblos.

A continuación se presenta un documento obrante en el Archivo Nacional de Chile, que refleja las concesiones de títulos que se hicieron a los caciques guaraníes durante el siglo XVII. Es un documento de gran valor que agrupa en forma cronológica una serie de nombramientos sumamente valiosos para el estudio de los liderazgos indígenas en las Misiones Jesuíticas.

Para realizar la transcripción se utilizó la forma modificada (literal modernizada), fiel literalmente, modificada para mejor comprensión de los lectores. ${ }^{13}$

\section{TRANSCRIPCIÓN}

\section{[ f. 1] Títulos de capitanes y de otros ministros de justicia y guerra que los gobernadores han dado a los indios del Paraná y Uruguay. ${ }^{14}$}

\section{Auto de nombramiento del Cacique Ayao}

[ f.2] Don Francisco de Céspedes, gobernador y Capitán general de estas provincias del Río de la Plata por su majestad, el Rey, por cuanto estoy informado que el cacique Ayao en las ocasiones que se han ofrecido con su persona y armas ha asistido con valor a las cosas de la guerra defendiendo los padres que lo doctrinan, y a sus sujetos en que se ha mostrado fiel y en la observancia de nuestra santa fe, a la cual ayuda a reducir a otros indios de aquellas provincias en lo que ha hecho gran servicio a su majestad, y yo estoy muy agradecido de ello y porque es justo del premio condigno a sus hazañas en nombre de su majestad elijo y nombro a dicho cacique Ayao por capitán para que, con la insignia que los tales acostumbran traer, acuda a las cosas de la guerra contra los indios infieles a

\footnotetext{
${ }^{11}$ Antonio Astrain. Ob. Cit. Pág. 103.

${ }_{12}$ Francisco Xarque. Ob. Cit. Pág 318

${ }^{13}$ Normas par la Transcripción de y Edición de Documentos históricos. Primera Reunión Argentina de Paleografía y Geografía. Universidad Nacional de Córdoba, 1957.
} 
los naturales sus vasallos y sujetos le acaten por su capitán y obedezcan sus mandatos en todo lo que se les ordenare y mandare, como sea en orden a su aumento y conservación, y para que de ello conste en este firmado de mi nombre y sellado con el sello de mis armas en Buenos Aires en 1 de Agosto de mil y seiscientos y veinte y nueve años. Don Francisco de Céspedes por mandado Alonso Agreda de Vergara, escribano mayor de gobierno. Da Vuestra Señoría título de capitán al cacique Ayao.

\section{Título de Maese de Campo del cacique Arambaré}

Don Pedro Lugo y Navarra caballero del hábito de Santiago, gobernador y capitán general de estas provincias [f. 3] del Paraguay por su Majestad, el Rey, por cuanto conviene nombrar personas de satisfacción y cuidado que haga oficio de maestre de campo en esta reducción de Itapúa y en la persona de vos, Don Antón Arambaré, concurren las dotes necesarias para el dicho oficio vos nombro crío, y elijo por tal maese de campo de esta dicha reducción y mando que os se aguardadas las preeminencias y franqueos que por razón de dicho oficio debéis gozar, y así mismo mando a todos los indios de esta reducción os tengan por tal maese de campo y os respeten, acaten y guarden vuestras órdenes en lo tocante al dicho oficio, en testimonio de lo cual os mande dar y di el presente firmado de mi nombre y sellado con el sello de mis armas y refrendado del presente escribano de vista que es fecho en esta dicha reducción de Itapúa en primero día del mes de febrero del mil y seiscientos y treinta y nueve años. Don Pedro de Lugo y Navarra por mandado del Señor gobernador. Martín de Orue de Zárate, escribano de visita.

Don Ventura Múxica de la orden de Santiago gobernador y capitán general de las provincias del río de la Plata por su majestad. Digo que por cuanto conviene al servicio de su majestad y defensa de las provincias del Uruguay sujetas a este gobierno donde los vecinos de San Pablo han entrado de mano armada y infestado los moradores de los pueblos y reducciones que en ella se han hecho por orden de su majestad nombrar persona o personas que gobiernen a los dichos indios moradores y naturales de ellas en [f.4] la guerra y defensa de suspueblos libertad y patria, y porque vos don Nicolás Nengirú capitán insolidium de la reducción de la Concepción, y vos don Francisco Bairoba capitán de la reducción de San Nicolás, y vos don Antonio Guaracica de la dicha reducción, y vos don Teodoro Iambatay de la reducción de San Carlos, y don Francisco Abie, capitán de la reducción de San Miguel, y don Roque Guiracazú, capitán de la reducción de San Cosme, sois personas que acudiréis al dicho oficio y defensa de las dichas provincias por la satisfacción que de vuestras personas tengo, en nombre de su majestad y en virtud de los poderes que para ello tengo que por ser notorios no van aquí insertos, os nombre por capitanes a guerra de las dichas provincias y reducciones para que viniendo el enemigo le podáis resistir y defender los dichos pueblos yreducciones, y prender a los culpables haciendo todas las prevenciones de guerra que según las cosas presentes se ofrecieren que para esto os doy a todos y cada uno de vosotros el poder que en tal caso es necesario y mando a todos los moradores de las dichas provincias y reducciones, vos obedezcan y ejecuten vuestras órdenes y mandatos, so las penas que

\footnotetext{
${ }^{14}$ Archivo Nacional de Chile. Vol. 203. (1625-1766) $\mathrm{N}^{\circ} 2$
} 
vos pareciere y juntamente mando las justicias y demás vecinos y moradores españoles de este gobierno y jurisdicción, no vos impidan ni pongan estorbo alguno pena de doscientos ducados aplicados a la cámara de su majestad, fecho en esta ciudad de la Trinidad y Puerto de Buenos Aires en dieciocho días del mes de diciembre de mil y seiscientos y cuarenta años, y no firmó el señor gobernador por estar impedido de la mano derecha, entregó el sello de sus armas y para que yo el presente escribano doy fe, siendo testigos[f. 5] Faustino de Prada y Jerónimo de Quevedo, Ambrosio de Sandoval, presentes, por mandado del señor gobernador. Alonso Agreda de Vergara, escribano mayor de gobernación.

Don Gerónimo Luis de Cabrera, gobernador, capitán y justicia mayor en estas provincias del Río de la Plata, Uruguay, Tapé y Biaça por el rey nuestro Señor Dios le guarde. Por cuanto estaba nombrado por capitán general a guerra y justicia mayor de las reducciones del Uruguay y demás tocantes a este gobierno don Nicolás Nengirú y falleció, y habían quedado los indios de las dichas reducciones sin capitán ni justicia para el buen gobierno de ellas, era necesario nombrar otro en su lugar de las dotes y calidades y suficiencia conveniente entre dichos naturales y porque por la experiencia se había reconocido, era el que convenía don Ignacio Abiarú que al presente es capitán de la reducción de la Asunción del Bororé, indio de valor que se había señalado en las ocasiones contra los portugueses de San Pablo que han venido a infestar las dichas reducciones, entre los demás indios en servicio de las dos majestades y de su patria y que era amado y temido y respetado entre todos los indios, le nombrase en el dicho cargo y por ser la relación hecha por el reverendo padre Diego Suárez de la Compañía de Jesús sacerdote a cuyo cargo está la reducción y enseñanza de los dichos indios y reducciones de la dicha provincia del Uruguay. Confiando de vos el dicho don Ignacio Abiarú y por el dicho informe en nombre de su majestad como Superior Capitán general y justicia mayor de las dichas provincias os nombro, elijo y proveo por Capitán General a Guerra, Justicia Mayor de las dichas reducciones de la provincia del Uruguay para que, [f.6] trayendo insignia de tal, uséis los dichos cargos y oficios y no otro ninguno indio, haciendo que acudan todos los dichos indios, sus mujeres e hijos a la doctrina para que sean enseñados y doctrinados en las cosas de la santa fe católica, no consintiendo estén casados infieles con cristianos ni cristianos con infieles, ni amancebados, ni que tengan juntas ni borracheras y hagan sus sementeras y estén con buena policía y ejemplo en servicio de Dios y si algunos indios cometieren delito por donde merezcan pena corporal los prenderéis y traeréis presos ante mí para que sean castigados y si algunos portugueses entraren con armas a invadir las reducciones como suelen, los prenderéis y traeréis ante mí para que proceda contra ellos como contra rebeldes a la real corona y en las cosas la vez que merezcan ejemplar castigo les haréis dar doce azotes y en todo acudiréis con mucho cuidado y puntualidad y mando a todos los caciques, curacas y demás indios os tengan y respeten por tal capitán general a guerra justicia mayor cumplan y hagan lo que les mandareis sin excusa alguna y os guarden las honras que por razón del dicho oficio se os deban guardar y deben gozar que yo en nombre de su majestad desde luego os recibo por los dichos cargos y oficios y os doy el poder y facultad que se requiere y es nuestro y de ello os manda dar la presente firmada de mi mano y sellada con el sello de mis armas y refrendada del infrascripto decreto de gobernación a quien mando deje un 
tanto en el registro de patentes [f. 7] que es fecha en la ciudad de la Trinidad Puerto de Buenos Aires en doce días del mes de enero de mil y seiscientos y cuarenta y tres años. Don Jerónimo Luis de Cabrera, por mandado del Señor gobernador, Alonso Agreda de Vergara, escribano mayor de gobernación. Vs. Nombra a don Ignacio Abiarú por capitán general a guerra y justicia mayor de los indios de las reducciones del Uruguay de este gobierno.

\section{Título de don Cristóbal de Aberabay}

El maestre de campo don Gregorio de Hinestrosa, gobernador y capitán general de estas provincias del Paraguay por el rey nuestro señor que Dios guarde, por cuanto en el pueblo y reducción de San Ignacio de las provincias del Paraná está sin persona que use oficio de corregidor y justicia mayor en el dicho pueblo y conviene le haya y porque vos don Cristóbal Aberabay, cacique principal de la dicha reducción, sois indio valeroso y de respeto y que con diligencia y cuidado acudiréis a lo que por mi os fuere mandado y que gobernaréis a todos los caciques y demás indios de ella manteniéndolos en paz y justicia atento a lo cual yo en nombre de su majestad y por virtud de los reales poderes que tengo que por su notoriedad no van aquí insertos os elijo, proveo y nombro por tal corregidores y justicia mayor del dicho pueblo y os doy poder y facultad para lo usar y ejercer trayendo vara alta de la real justicia en todas las cosas y casos al dicho oficio anejos y concernientes castigando culpados y premiando a los buenos acudiendo al reparo y conservación de la dicha reducción de indios y a otras mando a todos los alcaldes caciques principales y demás indios y a otras personas os hayan [ $\mathbf{f . 8}$ ] y tengan por tal corregidor y justicia mayor y os asistan, respeten y acaten guarden y cumplan vuestras órdenes y mandamientos so las penas que les impusiereis los cuales ejecutareis en los transgresores y os guarden y hagan guardar en todas las honras, franquicias y libertades y preeminencias que por razón de dicho oficio debéis haber y gozar sin que os falte ni mengüe cosa alguna por título de lo cual os mande dar y di el presente firmado de mi nombre y sellado con el sello de mis armas y refrendado del escribano de su majestad que es fecho en esta ciudad de la Asunción en veinte y cuatro días de noviembre de mil y seiscientos y cuarenta y un años. Don Gregorio de Hinestrosa por mandado del gobernador. Gómez de Gayoso escribano de su majestad.

\section{Nombramiento de Alférez de Simón Ayquaybe}

El maestre de campo Juan Arias de Saavedra teniente de gobernador y justicia mayor en la ciudad de Santa Fe y superintendente en ella y en la de San Juan de Vera de las Siete Corrientes con otras comisiones y órdenes para concluir esta guerra del valle de Calchaquí por el maestro de campo don Pedro de Baigorri, caballero de la orden de Santiago gobernador y capitán general de éstas provincias del Río de la Plata por el rey Nuestro Señor que Dios guarde digo que porque es preciso y conveniente nombrar oficiales de guerra en la que estoy siguiendo para su buena policía y está sin alférez la compañía del capitán don Pedro Enocoye cacique de la reducción de San Miguel y porque en la persona de don Simón Ayquaybe concurren las necesarias y es persona noble y de muchas prendas y vigilante en el servicio del rey nuestro [f. 9] señor en que se ha servido debajo de mi mano fielmente y dado buena cuenta de todo lo se le ha encargado y mostrado en todo buena disciplina y obediencia en virtud de lo cual y porque espero que lo prosiguiera en nombre de su 
majestad y en virtud de los poderes que tengo del señor gobernador de éstas provincias que por su notoriedad no van aquí insertos, le nombro, elijo, crío y señalo por alférez de la dicha compañía y capitán don Pedro Enocoye y a los soldados de la dicha compañía le haya y tenga por tal alférez guardándole y haciéndole guardar todas las preeminencias y inmunidades que por razón de dicho oficio le son debidas y se guardan y hacen guardar a los tales alférez en los reales y campos del rey mío señor y pueda traer y traiga la insignia y venablo de tal alférez y atento a su natural le reservo del derecho de la media annata por no estar ajustado por el señor juez del, hasta que otra cosa ordene y mande paso ante mi por defecto de escribano público ni real afirmada de mi mano y refrendada y sellada con el sello de mis armas y que es fecho en este valle de calchaquí y fuerte de Santiago de Baigorri en veinte días del mes de abril del año mil y seiscientos y cincuenta y seis años.

\section{Nombramiento de capitán del cacique Don Pedro Enocoye}

El maestre de campo Juan Arias de Saavedra, teniente de gobernador y justicia mayor y capitán a guerra en la ciudad de Santa Fe y superintendente en ella y en la de San Juan de Vera de las Siete Corrientes y con especiales comisiones para la pacificación de estas provincias por el Señor Maestre de campo don Pedro de Baigorri Ruiz caballero[f. 10] del orden de Santiago gobernador y capitán general de ella por el rey nuestro señor Dios le guarde y porque es preciso y conveniente según regla militar nombrar los oficiales convenientes para el buen gobierno y regimiento de los indios amigos y soldados que vinieron a servir de esta facción de las doctrinas de los venerables padres de la compañía de Jesús que han sido en cantidad de trescientos y cincuenta conducidos por los reverendos padres Diego Suárez y Juan de Roxas de la misma compañía para su educación de dichos y de todo este campo y fervorizarlos en el real servicio y porque con el premio crezcan en policía para con mayores efectos en el servicio del rey nuestro señor en nombre de su majestad y en virtud de los poderes que tengo del señor gobernador de ésta provincia que por su notoriedad no van aquí insertas y teniendo atención a la persona del cacique don Pedro Enocoye de la reducción de San Miguel que con la gente de su servicio vino a servir en su majestad en esta guerra como lo ha hecho con mucha aceptación, fidelidad y perseverancia por todo lo cual en virtud de lo que llevo referido, le nombro, elijo, crío y señalo por capitán de dichos indios de la dicha reducción y como a tal todo este campo así españoles como los soldados de su nación le acepten y respeten y los dichos soldados de su tercio guarden sus órdenes y las que por miles fueren dadas con toda puntualidad como se acostumbran guardar en todos los reales y campos del rey nuestro señor sin que falte cosa alguna con todas sus incidencias y dependencias y al dicho cargo anejo los expedientes y pueda usar y use el dicho cargo [f.11] con libre y general administración según reales placartes militares y atento a ser menores de edad y no estar ajustado el derecho de la media annata por estos naturales por el señor juez privativo de este derecho pueda usar el dicho cargo hasta que por el señor juez otra cosa se ordene y mande al cual título justo todo el campo se le había vos a toque de caja dándole la insignia por mi mano para que venga a noticia de todos los inobedientes serán castigados según fuero militar que es fecho en este Valle de Calchaquí y fuere del señor Santiago de Baigorri en veinte días del mes de abril de mil y seiscientos 
y cincuenta y seis años por ante mi y testigos por el efecto de escribano público ni real y refrendado con el sello de mis armas. Juan Arias de Saavedra.

El maestre de campo Juan Arias de Saavedra, teniente de gobernador y justicia mayor y capitán a guerra en la ciudad de Santa Fe y superintendente en ella y en San Juan de Vera de las Siete Corrientes y con especiales comisiones para la pacificación de éstas provincias por el señor Maestre de campo don Pedro de Baigorri Ruíz, caballero de la orden de Santiago, gobernador y capitán general de ellas por el rey nuestro señor Dios le guarde y porque es preciso y conveniente según regla militar nombrar los oficiales convenientes para el buen regimiento de los indios amigos y soldados que vinieron a servir de ésta facción de las doctrinas de los venerables padres de la compañía de Jesús que han sido en cantidad de trescientos y cincuenta conducidos por los reverendos padres Diego Suárez y Juan de Roxas de la misma compañía de Jesús par su educación de dichos indios mía [f. 12] y de todo este campo y fervorizarlos en el real servicio y porque con el premio crezcan en policía para mayores efectos en el servicio del rey en nombre de su majestad y en virtud de los poderes que tengo del señor gobernador de ésta provincia que por su notoriedad no van aquí insertos y teniendo atención la persona del cacique don Gaspar Añangue que con la gente de su tercio vino a servir a su majestad en esta guerra como lo ha hecho con mucha aceptación, fidelidad y perseverancia por todo lo cual y en virtud de los que llevó referido, le nombro, elijo, crío y señalo por capitán de dichos indios de dicha reducción de los apóstoles y como tal todo este campo así españoles como soldados de su nación lo acaten y recepten y los dichos soldados de su tercio guarden sus órdenes y las que por mí les fueren dadas con toda puntualidad como se acostumbran guardar en todos los reales y campos del rey nuestro señor sin que le falte cosa alguna con todas sus incidencias y dependencias y al dicho cargo con libre y general administración según reales placartes militares y atento a ser menores de edad y no estar ajustado el derecho de la media annata con estos naturales con el señor juez privativo de este derecho pueda gozar dicho cargo hasta que hasta que por el juez otra cosa se ordenare o mandare el cual título junto todo el campo se le habría vos a toque de caja dándole la insignia por mi mano para que venga a noticia de todos y los inobedientes sean castigados según fuero militar [f.13] que es fecho en este Valle de Calchaquí y fuerte del Señor Santiago de Baigorri en veinte días del mes de abril de mil y seiscientos y cincuenta y seis por ante mí y testigos para el efecto de escribano público y real y refrendado con el sello de mis armas. Juan Arias de Saavedra, testigo. Juan Bernal. Testigo Juan de las Casas. Testado $=$ provincias $=$ a otras $=$ no valen .

Concuerda con los títulos originales de donde se saca este traslado que para el dicho efecto exhibió el padre procurador general de la Compañía de Jesús Francisco Díaz Taño y volvió a llevar a su poder con las cuales fue corregidor y concertado y va cierto y verdadero y para que conste di el presente yo el maestre de campo Pedro de Baygorri, caballero del orden de Santiago gobernador y capitán general de estas provincias del Río de la Plata por su majestad ante mi y dos testigos por falta de escribano público y real en este papel común porno haber sellado en esta provincia en conformidad de lo acordado en esta razón fecho en esta ciudad de la Trinidad, puerto de Buenos Aires en veinte y seis de marzo de mil y 
seiscientos y cincuenta y nueve años.

Don Pedro de Baygorri

Juan Jiménez Trincado

Juan de Villoraz

\title{
Resumen
}

Existe una valiosa documentación que nos aproxima a través de interesantes descripciones a conocer desde la óptica jesuitica algunas características de los caciques guaraníes, sus acciones y su importancia en la consolidación de las reducciones a mediados del siglo XVII.

$\mathrm{Al}$ igual que en las reducciones administradas por otras órdenes religiosas, los caciques cumplieron una importante labor en la conformación de los pueblos y en los primeros tiempos de organización de cada uno de ellos. Las estrategias de aproximación de los padres de la Compañía a un determinado grupo indígena incluían en principio la relación con sus caciques y eran éstos quienes lograban que los otros líderes con sus parcialidades se acercaran. En este trabajo se presenta la transcripción del documento denominado «Títulos de Capitanes concedidos a los caciques guaraníes» cuyo original se encuentra en el Archivo Nacional de Chile. Consideramos que esta fuente será de gran valor para abordar la problemática de los liderzazos indígenas en la Misiones Jesuíticas y su rol en la conformación de las milicias.

$<$ encomiendas $><$ caciques $><$ misiones jesuíticas $>$

\begin{abstract}
A valuable documentation exists that approximates to us, through interesting descriptions, to the knowledge from the jesuitic point of view of some characteristics of the guaranies caciques, their actions and their importance in the consolidation of the reductions in the middle of the XVII century.

Like in the reductions administered by other religious orders, the caciques fulfilled an important work in the conformation of the towns and the first times of organization of each one of them. The strategies of approach of the parents of the Company to a certain indigenous group in principle included the relation with their caciques and these were who obtained that the other leaders with their parcialidades approached. This work presents the transcription of the document denominated "Titles of Captains granted to the guaraníes caciques" whose original it is in the National Archives of Chile. We considered that this source will be of great value to approach the problematic of the indigenous lidership in the Jesuitic Missions and its role in the conformation of the military services
\end{abstract}

$$
<\text { encomienda }><\text { caciques }><\text { misiones jesuítics }>
$$

